\title{
Diversidade sexual e ensino de ciências: buscando sentidos
}

\section{Sexual diversity and science teaching: seeking senses}

\author{
Leandro Jorge Coelho ${ }^{1}$ • Luciana Maria Lunardi Campos ${ }^{2}$
}

\begin{abstract}
Resumo: O objetivo desse estudo foi analisar os sentidos atribuídos por professores de Ciências e alunos à diversidade sexual. Foram utilizados: questionário, entrevista, produção de textos, análise documental e a técnica de grupo focal para a coleta de dados. De modo geral, os alunos possuem sentidos que reconhecem Lésbicas, Gays, Bissexuais e Transgêneros (LGBT) como “estranhos”, mesmo assim, acreditam que têm o dever de respeitar as escolhas de cada um. As travestis foram declaradamente apresentadas com repúdio por eles, sendo a homossexualidade e bissexualidade aparentemente mais aceitas. Os professores parecem manter aulas que não abordam estas questões, mesmo o Ensino de Ciências, sendo um momento privilegiado para problematizações sobre diversidade sexual e gênero. É necessário investir em discussões sobre esses temas na formação inicial e continuada de professores, buscando a construção de novos sentidos e práticas que se preocupem com o desvelamento de significados preconceituosos sobre gênero e diversidade sexual.
\end{abstract}

Palavras-chave: Diversidade sexual. Ensino de ciências. Sentido e significado. Educação sexual.

\begin{abstract}
The aim of this study was to analyze the understandings attributed by science teachers and students to sexual diversity. Questionnaires, interviews, text production, document analysis and focus group technique were used for data collection. In general, students have understandings that recognize Lesbian, Gay, Bisexual and Transgender (LGBT) as "strange", yet believe they have the duty to respect everyone's choices. They regarded transvestites with disapproval, while homosexuality and bisexuality seemed more accepted. Teachers seem not to discuss these subjects in class, even though Science teaching is a privileged situation in which to consider the significance of gender and sexual diversity. It is necessary to invest in discussions about these issues in initial and continued teaching courses, seeking the construction of new understandings and practices that problematize prejudice about gender and sexual diversity.
\end{abstract}

Keywords: Sexual diversity. Science teaching. Sense and significance. Sexual education.

\footnotetext{
${ }^{1}$ Faculdade de Ciências, Universidade Estadual Paulista (UNESP), Avenida Eng. Luiz Edmundo Carrijo Coube, 14-01, Vargem Limpa, CEP 17033-360, Bauru, SP, Brasil. E-mail: <leandrojc@gmail.com>

${ }^{2}$ Departamento de Educação, Instituto de Biociências, Universidade Estadual Paulista (UNESP), SP, Brasil.
} 


\section{Considerações iniciais}

A sexualidade humana tem sido objeto de estudos e pesquisas em diversas áreas, como Psicologia, Antropologia, Educação, Sociologia e Ciências Médicas, culminando na constituição de um conjunto de conhecimentos produzido social e historicamente pela humanidade sobre a temática. A produção de entendimentos sobre a sexualidade e sua vivência não se encontra livre de influências políticas, econômicas e sociais, o que faz com ela esteja "longe de ser uma expressão pura dos sentimentos e desejos humanos, pois é construída sócio historicamente, influenciada pelos interesses e ideologia da classe hegemônica" (MARIUZZO, 2003, p. 28). Para compreender significados e sentidos relacionados à diversidade sexual, é preciso considerar com relação à sexualidade humana.

O ser humano a expressa, como atividade que lhe é própria enquanto resultante de seu desenvolvimento biológico, psíquico e social [...]. Suas particularidades são determinadas por influências educacionais, econômicas, ideológicas, morais, culturais e políticas, que por sua vez, obedecem também a determinações sócio-históricas. (MARIUZZO, 2003, p. 11)

Sendo a sexualidade uma construção pessoal influenciada por fatores sociais e históricos, muitos são os significados construídos socialmente com relação à diversidade sexual. Louro (2000, p. 9) indica que é preciso buscar a superação da visão biologizante com relação à sexualidade e ao gênero, ressaltando que

[...] as possibilidades da sexualidade - das formas de expressar os desejos e prazeres - também são sempre socialmente estabelecidas e codificadas. As identidades de gênero e sexuais são, portanto, compostas e definidas por relações sociais, elas são moldadas pelas redes de poder de uma sociedade.

Considerando importante uma compreensão sócio-histórica da diversidade sexual e dos significados relacionados a ela, adotamos a Psicologia Histórico-Cultural, que é uma perspectiva crítica baseada no materialismo histórico-dialético, caracterizando-se por: uma concepção materialista que ressalta a existência da realidade material independente das ideias e pensamentos, e uma concepção dialética, que se baseia na contradição como característica fundamental de tudo o que existe, tendo sua superação como base das constantes transformações da realidade. Além disso, essa perspectiva é marcada pela historicidade, pois entende a história como "o movimento contraditório constante do fazer humano" (BOCK, 2001, p. 17), sendo o materialismo e a dialética fatores fundamentais para seu entendimento.

Nessa perspectiva, os significados são definidos como entendimentos construídos social e historicamente, compartilhados por um grupo de pessoas. Já os sentidos são a apropriação desses significados por um indivíduo, sendo influenciados pelas emoções e vivências pessoais (ASBAHR, 2011). É com esse olhar que buscamos entender significados histórico-sociais relacionados a orientações sexuais e identidades de gênero que fogem à norma heterossexual. 
Lésbicas, Gays, Bissexuais e Transgêneros (LGBT) são sujeitos historicamente considerados desviantes e estranhos, sendo a rejeição e negação das sexualidades não heterossexuais uma realidade que faz com que muitas LGBT vivam “numa espécie de vácuo identitário e sob o efeito perverso da alienação, com baixa autoestima, e incapazes de ações afirmativas" (MOTT, 2002, p. 144).

Acreditamos que a escola é um lugar privilegiado para a discussão e problematização de significados que excluem e estigmatizam estes sujeitos. Os professores de Ciências são, muitas vezes, os únicos profissionais reconhecidos como aptos a abordar temas relacionados à sexualidade com os alunos. Assim, é importante investigar os sentidos atribuídos por esses professores e alunos à diversidade sexual, procurando entender como se constroem esses entendimentos, como eles são influenciados socialmente, sobretudo no ambiente escolar e no Ensino de Ciências; e como se expressam em práticas e discursos. O objetivo deste estudo foi, portanto, analisar os sentidos atribuídos por professores de Ciências e alunos à diversidade sexual.

\section{As categorias significado e sentido na psicologia Histórico-Cultural}

Para a Psicologia Histórico-Cultural, as pessoas se desenvolvem propriamente como humanas ao transformarem a natureza, pois são modificadas ao se apropriarem destas transformações. A transformação do mundo objetivo gera uma transformação subjetiva que pode provocar novas necessidades, que levarão a novas objetivações e apropriações, num processo contínuo (MARTINS, 2007).

Para Leontiev (2004), o trabalho, além de unir o ser humano à natureza, possibilita o desenvolvimento da consciência. O autor acredita que a consciência com relação a objetos, ao trabalho e suas finalidades concretiza-se na linguagem, que é mediadora entre processos subjetivos e ações humanas, possibilitando a reflexão sobre ações e motivos.

Entendendo que a relação entre pensamento e linguagem é fundamental para a compreensão da consciência humana, Vygotsky (2000) indica que a unidade fundamental dessa relação é o significado da palavra, por ser um fenômeno da linguagem e do pensamento. As palavras relacionam-se dialeticamente com os pensamentos, tendo os significados como eixo unificador desta relação.

A palavra e seus significados representam apropriações dos indivíduos da produção material e intelectual da história humana (LEONTIEV, 2004). Embora as apropriações sejam individuais, existem conceitos e entendimentos estabelecidos historicamente, ou seja, apropriações compartilhadas por grupos de indivíduos, que constituem ideias difundidas e aceitas socialmente. Para Vygotsky (2000), os significados são generalizações das apropriações feitas historicamente pela humanidade, refletindo, portanto, um entendimento que não está preso à realidade concreta imediata, mesmo surgindo a partir da relação entre ser humano e mundo objetivo.

Os significados se expressam como "conceitos, saberes, modos de ação, independentemente da relação individual que os homens estabelecem com ela" (ASBAHR, 2011, p. 7). Algumas significações apresentam-se tão fortemente cristalizadas e difundidas histórico-socialmente, podendo ser invisíveis aos olhos de quem as apropria, o que pode promover a manutenção de sentidos e significados que sustentam, sem questionamento, algumas normas sociais existentes. 
Ao serem apropriados, os significados passam a fazer parte da subjetividade do sujeito, "passando a ocupar nele um lugar específico, a desempenhar um papel na vida desse indivíduo e em suas relações com o mundo" (MARTINS, 2007, p. 73-74). O sentido é exatamente esse papel individual ocupado pela subjetivação dos significados. Estando intimamente relacionado com a afetividade, as vivências e motivações pessoais, o sentido é uma formação mais dinâmica e complexa que o significado, sendo este "apenas uma pedra no edifício do sentido" (VYGOTSKY, 2000, p. 465).

Significados são apropriados constantemente pelos indivíduos e tornam-se sentidos, que influenciam suas motivações e posicionamentos na sociedade. Os sentidos são construídos em relação com os significados, podendo reforçar e manter significações existentes ou propor novos entendimentos (MARTINS, 2007). Assim, a produção individual de sentidos relaciona-se dialeticamente com a (re)produção social de significados.

Muitos significados são cristalizados histórico-socialmente, se tornando verdades ao longo da história humana. O processo de alteração dessas verdades pode ser longo e complicado devido à invisibilidade e disseminação de alguns significados nas relações e práticas sociais, que precisam ser desvelados e problematizados. Quando o tema é a diversidade sexual, muitos significados difundidos socialmente influenciam julgamentos relacionados à LGBT.

\section{Escola, diversidade sexual e Ensino de Ciências}

Foucault (1988) indica que, no final do século XVIII, diversas ciências passaram a discutir e estudar a sexualidade, e, com o desenvolvimento do capitalismo, surge um processo de repressão bastante sutil, que incentiva a discussão sobre o tema, o que levou pesquisadores e estudiosos a analisarem e quantificarem comportamentos sexuais. Estes estudos acabam por estabelecer classificações e padrões que indicavam o que seria normal e o que seria considerado um desvio, atribuindo uma visão patológica à sexualidade. A repressão sexual ocorre de maneira velada, pois a dominação dos corpos e sexualidades se dá por mecanismos complexos de vigilância e normatização, "por meio da produção e da inscrição da sexualidade, e não pela sua negação e proibição” (BRAGA, 2008, p. 28).

Muitos significados construídos sócio-historicamente com relação à sexualidade são marcados por uma visão reducionista e biologizante, que desconsidera aspectos histórico-sociais na construção e vivência da sexualidade humana. Assim, criam-se visões patologizantes que se transformam em significados compartilhados socialmente, entendendo que os desvios e perversões devem ser evitados, marginalizados e excluídos, enquanto existe um padrão sexualmente "correto" que deve ser seguido.

As significações sobre sexualidade atendem a interesses da classe dominante, regulando os corpos e as sexualidades, definindo comportamentos, atitudes e significados que distinguem os "normais" dos desviantes. Mariuzzo (2003, p. 28) ressalta que a sexualidade "é um ponto muito delicado e estratégico para os interesses dominantes se ocuparem, pois ao criar-se crenças, dogmas religiosos, mantêm-se os indivíduos alienados de seus próprios corpos", assim, eles não serão capazes de perceber as contradições e injustiças a que estão submetidos.

Ao indicarem a norma e seus desvios, os significados sobre sexualidade levam muitos indivíduos a buscarem um padrão socialmente aceito como normal, fazendo-os perderem 
uma visão aberta e dinâmica com relação à sua própria sexualidade. Esta vigília constante pode impedir que as pessoas percebam como seus corpos e suas vivências afetivas e sexuais são controlados e influenciados por significações compartilhadas, muitas vezes, de forma "natural" ou imperceptível, em diversos contextos sociais.

[...] a família, com o seu silêncio ou discursos repressores e confusos; a igreja, com seus valores dogmáticos; a escola, pela sua omissão de responsabilidade na formação do ser humano; os meios de comunicação, com a exacerbação e banalização de sentimentos, e pela mercantilização do corpo humano, do afeto e do sexo, são algumas das instâncias que mais interferem na formação da concepção de sexualidade no indivíduo. (MARIUZZO, 2003, p. 27)

Significados amplamente difundidos que indicam o que é desvio e o que é normal fortalecem dificuldades no reconhecimento da diversidade sexual enquanto legítima. Discutir sobre diversidade sexual é defender o reconhecimento de diferentes possibilidades de vivência da sexualidade, sobretudo, no que se refere às orientações sexuais e identidades de gênero que fogem ao padrão heterossexista da sociedade atual.

Embora presentes em todos os espaços sociais, os indivíduos LGBT possuem um histórico social marcado pelo preconceito e marginalização, que faz com eles ainda tenham que lutar por direitos de cidadania básicos. É fundamental entender que a negação social de direitos LGBT acontece por meio de um sistema normatizador e normalizador que

[...] tem sua eficácia garantida por mecanismos de introjeção e controle (sexualmente diferenciados e sexualmente diferenciantes) ligados à crença de que a determinado sexo deva corresponder, de modo biunívoco, um determinado gênero, o qual, por sua vez, implicaria um determinado direcionamento do desejo sexual. (JUNQUEIRA, 2009, p. 375-376)

Assim, existiria uma correspondência natural entre sexo biológico, orientação do desejo sexual e identidade de gênero, e essa relação tem como base a heterossexualidade, o que implica a exclusão e marginalização de sujeitos que experienciam outras formas de vivência da orientação sexual ou identidade de gênero. De acordo com estes significados, só são considerados normais homens masculinos que se atraem por mulheres femininas, e mulheres femininas que se atraem por homens masculinos. Louro (2009) entende que, aí, se encontra a base fundante da heteronormatividade.

Esse alinhamento (entre sexo-gênero-sexualidade) dá sustentação ao processo de heteronormatividade, ou seja, à produção e à reiteração compulsória da norma heterossexual. Supõe-se, segundo essa lógica, que todas as pessoas sejam (ou deveriam ser) heterossexuais [...]. Os outros, que fogem à norma, poderão, na melhor das hipóteses ser reeducados, reformados, [...]; quando não forem simplesmente excluídos, ignorados ou mesmo punidos. (LOURO, 2009, p. 90, grifo do autor) 
Vivemos em uma sociedade heteronormativa, que está estruturada de forma a negar, excluir e estigmatizar aqueles que não seguem o alinhamento sexo-gênero-orientação sexual. Para manter a norma heterossexual, é necessário reiterar, constantemente, a heterossexualidade, o que acontece "de forma continuada e constante (muitas vezes, sutil) pelas mais diversas instâncias sociais" (LOURO, 2009, p. 90). A constante reiteração da heterossexualidade e a consequente exclusão e marginalização da população LGBT estão fortemente articuladas às significações relacionadas ao gênero.

Basta lembrar o quanto é comum atribuir a um homem homossexual a qualificação de "mulherzinha" ou supor que uma mulher lésbica seja uma mulher-macho. A transgressão da norma heterossexual não afeta apenas a identidade sexual do sujeito, mas é muitas vezes representada como uma "perda" do seu gênero "original". (LOURO, 2009, p. 91)

A crença de que existe um gênero "original" ou "natural” é biologizante, pois o sexo biológico determinaria, automaticamente, o gênero do indivíduo. É preciso superar esse determinismo enfatizando o caráter histórico-social da construção do gênero. Feminino e masculino são significações construídas histórico-socialmente pelas mais variadas sociedades humanas "segundo suas tradições culturais e interesses econômicos e políticos defendidos pela classe hegemônica, nos diversos momentos históricos” (MARIUZZO, 2003, p. 25).

A discriminação contra LGBT é um fenômeno estruturante das relações entre indivíduos e, também, da própria dinâmica social e cultural, estando presente em todos os seus âmbitos: na família, no sistema educacional, na legislação, no sistema de saúde, no sistema judicial, na polícia etc. (JUNQUEIRA, 2009).

Pensar sobre significações consolidadas historicamente a respeito da diversidade sexual de forma dialética, implica entender que elas podem (e devem) ser alteradas. A escola se constitui como um dos espaços propícios para que ocorra o desvelamento de contradições do mundo objetivo, podendo levar a novas ações e relações que busquem alterar e problematizar ideias cristalizadas e aceitas socialmente. Mesmo com esse potencial de desvelamento do mundo, na escola, estão presentes significações pautadas na heteronormatividade e na exclusão de LGBT.

Louro (2000) indica que a escola constitui-se como um espaço de (re)produção de sujeitos padronizados, baseados em representações brancas, masculinas e heterossexuais. Significados relacionados à diversidade sexual legitimam a discriminação de LGBT também na escola, sendo necessário investir no desvelamento e ressignificação de práticas e discursos, compreendendo seus condicionantes sociais e históricos.

Os professores parecem ainda não assumir este compromisso, sendo que a sexualidade entendida em seu aspecto social e histórico continua a ser negligenciada nos currículos escolares, na prática docente e nos cursos de formação de professores (BONFIM, 2009). Quando abordada na escola, de um modo geral, é reduzida a questões ligadas à biologia e reprodução. Este reducionismo tem como consequência a manutenção de significados biologizantes, como a crença na existência de um "gênero original" que corresponde automaticamente ao sexo biológico (LOURO, 2009).

Embora seja um tema transversal nos Parâmetros Curriculares Nacionais (PCN) (BRASIL, 1997), a educação sexual é tratada, na maioria dos casos, como uma tarefa dos professores 
de Ciências e Biologia que, de maneira geral, se limitam aos aspectos fisiológicos e médicos (BONFIM, 2009). Para Silva (2005), o corpo humano enquanto conteúdo escolar é uma especificidade do Ensino de Ciências e vem sendo apresentado a partir de um olhar biomédico, de maneira fragmentada e deserotizada. Com a sexualidade apresentada desconectada de aspectos históricos ou culturais, o Ensino de Ciências acaba por contribuir para a (re)produção do heterossexismo, da homofobia e de significações excludentes relacionadas ao gênero.

É preciso investir em esforços que busquem desvelar e problematizar significados e sentidos expressos em piadas, práticas e discursos, que marginalizam e excluem as sexualidades não heterossexuais. Um espaço com potencial pouco explorado para tais problematizações é o Ensino de Ciências.

\section{Fundamentos e aspectos metodológicos}

Esta foi uma pesquisa qualitativa que teve por interesse analisar os sentidos atribuídos por professores de Ciências e alunos do $8^{\circ}$ ano do Ensino Fundamental à diversidade sexual. Para investigar estes sentidos, utilizamos: questionários, entrevistas semiestruturadas, análise de textos produzidos pelos alunos, grupos focais e anotações do diário de campo.

Visando uma aproximação inicial com as realidades escolares, e para auxiliar na definição das duas escolas em que foi realizada a coleta de dados, realizamos um levantamento nos Livros de Ocorrência das 12 escolas Estaduais de um município do interior de São Paulo, com a permissão de cada diretor. O Livro de Ocorrências é um documento utilizado para registrar acontecimentos relacionados à indisciplina, brigas ou demais situações ocorridas na escola. Cada livro foi lido buscando identificar situações em que o preconceito relacionado à diversidade sexual e de gênero estivesse presente. Durante as visitas, muitos diretores relataram suas impressões sobre o preconceito contra LGBT na escola e elas foram anotadas no diário de campo.

Após a análise dos livros e relatos dos diretores, percebemos que o Livro de Ocorrências parece não ser o melhor documento para a identificação de situações de preconceito relacionadas à diversidade sexual na escola, e que seria impossível escolher as escolas que participariam do estudo usando como critério o número de ocorrências, já que ele foi pouco significativo. Selecionamos as escolas em que os diretores, durante a conversa com o pesquisador, enfatizaram a existência de alunos, professores e funcionários LGBT ou de situações de preconceito. Assim, escolhemos duas escolas designadas A e B.

Utilizamos questionários, grupos focais e produção de textos para coletar os dados referentes aos sentidos dos alunos sobre a diversidade sexual, sendo que 106 alunos do $8^{\circ}$ ano das duas escolas responderam ao questionário, 27 participaram dos grupos focais e 115 alunos participaram da produção de um pequeno texto referente à suas impressões sobre uma foto do casamento entre a cantora Daniela Mercury e a jornalista Malu Verçosa.

Realizamos duas entrevistas com cada professor, seguindo roteiros semiestruturados. As entrevistas tiveram como principais objetivos: analisar os sentidos produzidos por eles com relação à diversidade sexual e entender que importância creditam à problematização da diversidade sexual em sala de aula.

A análise de dados teve como referência as ideias de Aguiar e Ozella (2006), cuja proposta de análise começa com repetidas leituras do material e a seleção de pré-indicadores, que 
são ideias que aparecem com mais frequência ou ênfase. Estes são organizados em indicadores, por sua similaridade ou contraposição. A partir daí, são construídos núcleos de significação, agrupando indicadores que se relacionam e indicam aspectos centrais para a compreensão dos sentidos, guiados pelo objetivo do estudo. A análise dos núcleos de significação parte de um processo intranúcleo para uma articulação entre núcleos, buscando a discussão de questões específicas e suas articulações com o contexto social e histórico (AGUIAR; OZELLA, 2006). Nesse processo, consideramos separadamente os dados relacionados aos alunos (questionários, grupos focais e comentários sobre a foto), e os dados das entrevistas de cada professor (analisados individualmente).

Considerando que o objetivo do estudo foi analisar os sentidos atribuídos por professores de Ciências e alunos à diversidade sexual, os núcleos construídos buscaram a identificação de temas que elucidassem os entendimentos dos sujeitos, sobretudo, com relação: às identidades LGBT, sua (não) aceitação social, sentidos relacionados a masculinidade e feminilidade, e articulações entre escola, diversidade sexual, e Ensino de Ciências.

\section{Análise e discussão dos dados}

A discussão dos dados começará por análises separadas referentes aos alunos, à professora da escola A e ao professor da escola B, seguindo para articulações e discussões comuns entres eles. Os trechos em itálico são transcrições de falas dos alunos sendo: M - mulher, H homem e $\mathrm{P}$ - pesquisador, e o número corresponde à identificação de cada aluno no Grupo Focal.

Ao analisarmos os dados coletados junto aos alunos, por meio do questionário, das reuniões do Grupo Focal e dos textos produzidos a partir da foto, identificamos 83 pré-indicadores, organizados em 12 indicadores. Após a identificação dos indicadores, passamos à organização e nomeação dos núcleos de significação. Seguindo a sugestão de Aguiar e Ozella (2006), extraímos expressões das falas dos sujeitos para nomear os três núcleos (Quadro 1).

No primeiro núcleo de significação, "Existem mulheres masculinas e homens femininos": orientações sexuais e identidades de gênero estranhas, estão reunidas ideias acerca das identidades LGBT e significações sobre masculinidade e feminilidade apresentadas pelos alunos. Muitos deles consideram a homossexualidade estranha e diferente, mas outros a veem com naturalidade, indicando acreditar que "se as pessoas se amam, é normal!" ( $\mathrm{M}$ - comentário da foto). A falta de esclarecimento sobre algumas orientações sexuais e identidades de gênero apareceu nas falas dos alunos, sendo detectadas confusões entre transexualidade e bissexualidade nos questionários e nos grupos focais.

De maneira geral, os sentidos dos alunos parecem pressupor a masculinidade aos homens e a feminilidade às mulheres, como mostra o trecho de uma reunião do grupo focal:

\footnotetext{
$\mathrm{P}$ - Todo homem tem que ser masculino?

M5 - Não, ele que escolbe.

H1 - Lógico, se é homem, tem que ser masculino!

M4 - Se nasceu homem devia ser né...

M1 - É devia, mas não é...
} 
Quadro 1. Indicadores e núcleos de significação referentes aos alunos

\begin{tabular}{|c|c|}
\hline Núcleos de significação & Indicadores \\
\hline $\begin{array}{l}\text { "Existem mulheres masculinas e } \\
\text { homens femininos": orientações } \\
\text { sexuais e identidades de gênero } \\
\text { estranhas }\end{array}$ & $\begin{array}{l}{ }^{\circ} \text { Homossexualidade } \\
{ }^{\circ} \text { Bissexualidade } \\
{ }^{\circ} \text { Transexualidade } \\
{ }^{\circ} \text { Travestilidade } \\
{ }^{\circ} \text { Masculino e Feminino }\end{array}$ \\
\hline $\begin{array}{l}\text { "O homem foi feito para a mulher } \\
\text { e a mulher para o homem": exclusão } \\
\text { e marginalização de pessoas LGBT }\end{array}$ & $\begin{array}{l}\text { ○ A não-aceitação de sujeitos LGBT } \\
{ }^{\circ} \text { Explicações para a não-aceitação de LGBT } \\
\circ \text { O que é errado e o que é pior ainda }\end{array}$ \\
\hline $\begin{array}{l}\text { "Não critico, mas não apoio": } \\
\text { posicionamentos e valores que } \\
\text { permeiam vivências pessoais }\end{array}$ & $\begin{array}{l}{ }^{\circ} \text { O dever de respeitar as individualidades e escolhas pessoais } \\
{ }^{\circ} \text { Eu e os sujeitos LGBT: estranhamento e aceitação } \\
{ }^{\circ} \text { Direito e igualdade } \\
{ }^{\circ} \text { Necessidade de discussões }\end{array}$ \\
\hline
\end{tabular}

Fonte: elaborado pelos autores.

Apesar de reconhecerem a existência de homens femininos e mulheres masculinas, ambos são associados rapidamente à homossexualidade. Esses sentidos parecem se basear em significados que pressupõem uma relação diretiva entre sexo, gênero e orientação sexual, levando à estigmatização não só de LGBT, mas de todos que fogem a este alinhamento.

A maioria dos alunos considera estranhas ou confusas as identidades bissexual, transexual e travesti. Bissexuais são considerados diferentes por serem "indecisos" com relação a por quem se atraem. De modo geral, os alunos não reconhecem como legítima a identidade travesti, considerando que seria apenas uma fase de experimentação da feminilidade, e não uma construção identitária definitiva.

O segundo núcleo, intitulado "O homem foi feito para a mulher, e a mulher para o homem": exclusão e marginalização de pessoas LGBT, reúne ideias e vivências sobre a nãoaceitação de pessoas LGBT. Como mostra o nome do núcleo, a ideia determinista de que "o homem foi feito para a mulher, e a mulher para o homem" esteve presente em todos os encontros com os alunos e, também, nos questionários e textos produzidos.

Grande parte dos alunos reconhece que LGBT são alvos constantes de discriminações no convívio social e, segundo eles, o preconceito não afeta lésbicas, gays, transexuais e travestis de forma idêntica:

M5 - As lésbicas não têm muito esse preconceito, têm muito respeito com elas.

M6 - São poucos os que desrespeitam as lésbicas.

M5 - Bem poucos.

$\mathrm{P}-$ Por quê? 
M5 - Porque é menina né. Menina sempre é delicada, não importa o que ela é, ela é delicada.

M2 - E elas são gente boa!

M6 - Mas têm umas que não são delicadas! Têm umas que querem ser homem.

M2 - Mas tem sentimento né!

Os alunos acreditam que existe uma maior rejeição social relacionada aos gays que às lésbicas, justificada pela delicadeza e sentimentalidade intrínsecas das mulheres. Concordamos com Louro (2000) ao dizer que significados machistas e heteronormativos levam a uma maior vigilância das identidades masculinas, que são denunciadas a qualquer deslize que afaste o homem do padrão heteronormativo instituído, legitimando significados que parecem estigmatizar e excluir mais gays do que lésbicas.

Com relação às travestis, o ódio presente nas falas foi declarado e perturbador:

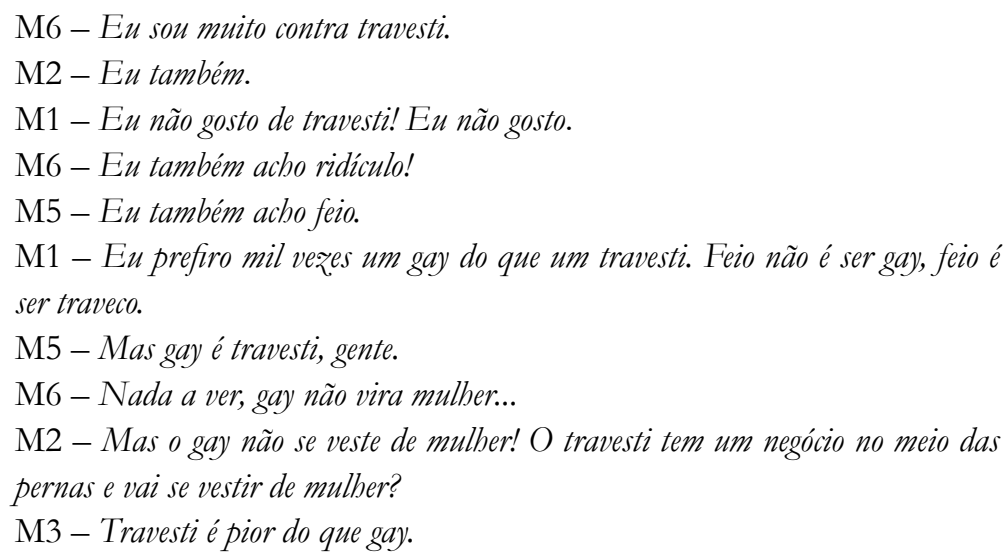

Os alunos parecem possuir níveis de aceitação com relação a LGBT, e as travestis ocupariam o lugar mais próximo à total não-aceitação. Com uma realidade repleta de preconceitos, travestis e transexuais, geralmente, possuem relações traumáticas com a escola, levando a uma alta taxa de evasão, muitas vezes, por não suportarem as humilhações, piadas e violência praticamente diárias.

O terceiro e último núcleo relacionado aos alunos foi chamado "Não critico, mas não apoio": posicionamentos e valores que permeiam vivências pessoais, e possui ideias relacionadas ao respeito às individualidades e à igualdade, além de alguns posicionamentos pessoais referentes aos sujeitos LGBT e ao casamento entre pessoas do mesmo sexo.

Nos comentários sobre a foto do casamento entre duas mulheres, alguns alunos consideraram aquele casamento diferente, mesmo reconhecendo o afeto entre elas: "Eu vejo o casamento de duas mulheres que se gostam muito e querem ser felizes juntas. Eu acho que é diferente e nunca vi igual em outros casamentos" ( $\mathrm{H}$ - comentário da foto).

Parte dos alunos parece possuir sentidos que reconhecem e valorizam a conquista da legalização do casamento entre pessoas do mesmo sexo, considerando-o normal: "Eu acho muito legal que o casamento gay foi legalizado em alguns lugares pois todos têm o direito de escolher quem amam e viver a vida juntos" ( $\mathrm{M}$ - comentários da foto). 
Outros comentários indicam sentidos contraditórios, que anunciam "não ter nada contra", mas são seguidos de comentários preconceituosos: "Não tenho nada contra, mas acho que se Deus fez o homem e a mulher era para fazer a união com o sexo oposto. E não com pessoas do mesmo sexo, mas eu respeito" ( $\mathrm{H}$ - comentário da foto).

Quando questionados sobre como aprenderam o que sabem sobre a diversidade sexual, a maioria indicou a mídia como principal fonte, sendo a segunda fonte mais indicada o professor, reiterando a importância deste profissional na construção de sentidos relacionados à diversidade sexual e gênero pelos alunos.

A maior parte dos alunos que participou do Grupo Focal disse nunca ter discutido na escola sobre diversidade sexual. As falas indicam que os alunos reconhecem a necessidade de que o tema seja abordado na escola, e, segundo eles, a discussão, provavelmente, ocorreria na disciplina de Ciências, por ser uma matéria que inclui corpo humano e reprodução.

De modo geral, os dados apresentam indícios de que os significados atuais com relação à diversidade sexual, muitos deles pautados na heteronormatividade, refletem-se nos sentidos construídos pelos alunos sobre esta diversidade. Mesmo vivendo em uma sociedade extremamente marcada por significados heteronormativos que regulam os corpos, sexualidades, instituições e discursos, alguns alunos reconhecem a legitimidade das identidades LGBT. Mesmo assim, a não-discussão na escola sobre a diversidade sexual parece manter sentidos confusos e preconceituosos com relação às orientações sexuais e identidades de gênero por parte dos alunos. O Ensino de Ciências, muitas vezes, é o único momento em que ocorrem ações voltadas ao debate da sexualidade na escola, e nele continua a ser apresentado um corpo e uma sexualidade desconectados de questões históricas e sociais.

Os dados referentes às duas entrevistas com a professora da escola A foram organizados da mesma maneira que os coletados junto aos alunos: inicialmente, foram identificados 71 pré-indicadores, organizados em dez indicadores, que foram reunidos em quatro núcleos de significação, como mostra o Quadro 2.

Quadro 2. Núcleos de significação e seus indicadores referentes à professora da escola $\mathrm{A}$

\begin{tabular}{|c|c|}
\hline Núcleos de significação & Indicadores \\
\hline $\begin{array}{l}\text { "A escola é o lugar para formar novas } \\
\text { percepções sobre a diversidade sexual": } \\
\text { sexualidade e diversidade sexual na escola }\end{array}$ & $\begin{array}{l}{ }^{\circ} \text { Outros professores e a diversidade sexual } \\
{ }^{\circ} \text { A educação sexual escolar } \\
{ }^{\circ} \text { Os alunos e a Diversidade sexual }\end{array}$ \\
\hline $\begin{array}{l}\text { "Quer que eu fale sobre isto? Eu vou!": } \\
\text { sexualidade e Ensino de Ciências }\end{array}$ & $\begin{array}{l}{ }^{\circ} \text { Minhas práticas de educação sexual } \\
{ }^{\circ} \text { O Ensino de Ciências e a sexualidade }\end{array}$ \\
\hline $\begin{array}{l}\text { "Fico indignada com alunos } \\
\text { preconceituosos": aceitação e exclusão de } \\
\text { LGBT }\end{array}$ & $\begin{array}{l}{ }^{\circ} \text { Posicionamentos e emoções pessoais } \\
{ }^{\circ} \text { Os outros e a diversidade sexual } \\
{ }^{\circ} \text { Os sujeitos LGBT }\end{array}$ \\
\hline $\begin{array}{l}\text { "Não fui muito preparada sexualmente": } \\
\text { a minha educação sexual }\end{array}$ & $\begin{array}{l}\text { ' Família, sexualidade e diversidade sexual } \\
{ }^{\circ} \text { Formação relacionada à sexualidade e diversidade sexual }\end{array}$ \\
\hline
\end{tabular}

Fonte: elaborado pelos autores. 
No núcleo intitulado: "Fico indignada com alunos preconceituosos": aceitação e exclusão de LGBT, estão reunidas ideias relacionadas aos sentidos da professora sobre os sujeitos LGBT, sua não-aceitação social e alguns posicionamentos e emoções pessoais.

A professora parece possuir uma compreensão positiva com relação às sexualidades não heterossexuais, reconhecendo a legitimidade das identidades LGBT. Apesar de reconhecer que existem avanços na forma como a diversidade sexual é vista em nossa sociedade, a professora acredita que ainda existe muito preconceito contra LGBT.

Como ressalta o título do núcleo, ela se mostrou indignada diante de posturas e comentários preconceituosos vindos de seus alunos, levando ao não-silenciamento diante de situações de discriminação.

No núcleo: "A escola é o lugar para formar novas percepções sobre a diversidade sexual": sexualidade e diversidade sexual na escola, reunimos ideias relacionadas à educação sexual escolar e percepções sobre como a diversidade sexual é vista pelos alunos e colegas.

Sobre alguns colegas de profissão, a professora diz perceber discursos que parecem possuir indícios de sentidos relacionados ao preconceito sutil: "Eu tenho outros colegas assim que... pensam que não são preconceituosos, né? Mas fazem os comentários". Professores preconceituosos que não conseguem perceber e problematizar seus próprios preconceitos, provavelmente, promoverão a manutenção de práticas e discursos que discriminam, excluem e diminuem LGBT no ambiente escolar.

Assim como os alunos, a professora acredita que existe uma maior negação de sujeitos transgêneros, que seriam mais discriminados do que homossexuais: "Ainda existe opreconceito com os homossexuais, se eles forem pra escola travestidos, imagina!'. Para ela esse preconceito faz com que alunos transgêneros tenham de reprimir seus desejos: "Acho que eles acabam se reprimindo. Eu acho. Eu já vi ex-alunos transexuais, depois da escola. Que na época da escola não eram. Mas na escola, nunca vi". Os relatos indicam a ausência de alunos transgêneros na escola, reforçando a situação precária a que estão submetidas crianças e adolescentes transexuais e travestis em idade escolar.

Durante a entrevista, a professora disse acreditar que a mídia televisiva ensina mais do que a escola aos alunos, quando se trata da sexualidade: "Acho que o que mais ensina eles é a televisão e a mídia. Ensina muito mais do que a escola, não que seja melhor, mas ela ensina mais. Às vežes já ensina com todos os seus valores, preconceitos".

A professora acredita que seus alunos também são bastante influenciados por significados familiares e religiosos. Segundo ela, "eles vêm com muitas informaçôes erradas, e assim pela metade, só sabe um pouco, acha que sabe, mas não sabe". Diante da falta de informação e dos preconceitos que vê em seus alunos, a professora acredita que, na escola, é possível criar novos sentidos sobre a sexualidade.

Em suas falas, ela ressalta a ausência de orientações e projetos direcionados à diversidade sexual: "As nossas orientações na área da sexualidade nunca são focadas para a diversidade sexual. É só pra gravidez na adolescência, têm os projetos lá de prevenção de gravidez̧, de prevenção de doenças". Diante da ausência de orientações sobre o tema, e vendo que seus alunos possuem muitas dúvidas e incertezas sobre a sexualidade, a professora parece possuir um sentido que valoriza a realização de ações relacionadas à sexualidade em sala de aula, mas reconhece a dificuldade em inserir e discutir o tema diversidade sexual.

O próximo núcleo, intitulado “Quer que eu fale sobre isto? Eu vou!": sexualidade e Ensino de Ciências, possui relatos que indicam que a professora se interessa por questões rela- 
cionadas à sexualidade e educação sexual, e, por isso, sempre trabalhou com o tema. A falta de conhecimentos sobre sexualidade, dos alunos, parece ser uma motivação para a abordagem do assunto: "Eu nunca tive vergonha, porque eu achava que meus alunos tinham que saber! Eu estava cansada de ver aquelas alunas sairem correndo todas com a calcinha vermelha porque teve uma menstruação e não sabia o que estava acontecendo".

Mesmo reforçando que a sexualidade é um tema transversal e deve ser abordada por todos as disciplinas, ela reconhece um papel diferenciado do Ensino de Ciências: "Ciências tem a obrigação de abordar a sexualidade dentro da escola. Essa formação tem que vir em Ciências eu acho. Não é reprodução, porque a gente tem o conteúdo de reproducão comparativa... é outra coisa! Eu acho que o professor tem que abordar a sexualidade".

É preciso superar a visão reducionista da sexualidade que, geralmente, é apresentada na escola, buscando uma compreensão que leve em consideração aspectos históricos e sociais. É no Ensino de Ciências que são abordadas questões relativas ao corpo (SILVA, 2005), levando esse profissional a ser reconhecido como detentor de conhecimentos relacionados às questões reprodutivas e sexuais, ficando evidente o papel central que os professores de Ciências, muitas vezes, assumem nas escolas quando se trata da sexualidade na escola.

Mesmo com interesse e motivação para realizar atividades relacionadas à sexualidade na escola, a professora reconhece a carência na formação do professor de Ciências para trabalhar o assunto. É necessário desenvolver ações formativas que preparem os professores de Ciências para a abordagem da sexualidade (e não só da reprodução) na escola; e é preciso, também, sensibilizar e conscientizar os demais professores de que a sexualidade não é um tema exclusivo do Ensino de Ciências.

Mesmo com sentidos que a motivam a abordar a sexualidade na escola, a diversidade sexual nunca foi alvo de discussões propostas pela professora em sala de aula. Ela diz que o tema é delicado, e não existem orientações sobre como abordar o assunto: "Não tem uma coisa direcionada assim... se tá certo você falar ou não, você levantar a polêmica ou não, entendeu? Então eu acho que quando surge, quando eu estou falando nas aulas de educação sexual e surge este assunto, aí nós fazemos comentários".

O último núcleo referente às falas da professora ("Não fui muito preparada sexualmente": minha educação sexual) reúne ideias relacionadas à sua formação em sexualidade tanto na escola, como no ambiente familiar. A professora apresenta seu pai como uma pessoa aberta ao diálogo e crítica, e ele parece ter sido uma figura importante para sua construção de sentidos com relação à sexualidade, o que parece ter refletido no reconhecimento das sexualidades não heterossexuais enquanto legítimas e naturais.

A professora reconhece a falta de preparo de sua formação inicial, onde não participou de nenhuma discussão relacionada à diversidade sexual. Ao se lembrar de suas aulas de educação sexual no Ensino Básico, a professora demonstra indignação: "Eu aprendi sożinha! Aprendi com dezoito anos quando eu arrumei um namorado que eu descobri que tinha que unir os dois órgãos sexuais, entendeu? E que isso também era... que tinha relação a reprodução com o prazer sexual. Pra mim era desconectado essas duas coisas, olha que absurdo!”. A fala da professora ressalta a importância de associar sexualidade e prazer e "admitir práticas sexuais distintas daquelas voltadas à reprodução, considerar a existência de uma subjetividade no prazer humano” (FURLANI, 2007, p. 13).

A análise dos dados referentes ao professor da escola B começou com a identificação de 67 pré-indicadores, organizados em 9 indicadores, que foram reunidos em três núcleos de significação, como mostra o Quadro 3. 
Quadro 3. Núcleos de significação e seus indicadores referentes aos dados do professor da escola B

\begin{tabular}{|c|c|}
\hline Núcleos de significação & Indicadores \\
\hline $\begin{array}{l}\text { "A escola ainda tem dificuldades em } \\
\text { trabalhar temas fora do que é normal": } \\
\text { diversidade sexual na escola }\end{array}$ & $\begin{array}{l}{ }^{\circ} \text { Diversidade sexual na escola } \\
{ }^{\circ} \text { Os professores e a diversidade sexual } \\
{ }^{\circ} \text { Os alunos e a diversidade sexual }\end{array}$ \\
\hline $\begin{array}{l}\text { "Quando os alunos trazem ideias } \\
\text { preconceituosas, fico sem reação": } \\
\text { sexualidade e Ensino de Ciências }\end{array}$ & $\begin{array}{l}{ }^{\circ} \text { Minhas práticas de Educação Sexual } \\
{ }^{\circ} \text { Formação e sexualidade } \\
{ }^{\circ} \text { O Ensino de Ciências e a sexualidade }\end{array}$ \\
\hline $\begin{array}{l}\text { "O preconceito está em nós desde que } \\
\text { somos crianças": questões relacionadas } \\
\text { aos sujeitos LGBT }\end{array}$ & $\begin{array}{l}{ }^{\circ} \text { Aceitação e não-aceitação de LGBT } \\
{ }^{\circ} \text { Explicações para a homo e bissexualidade } \\
{ }^{\circ} \text { Ser gay, se assumir e ser aceito }\end{array}$ \\
\hline
\end{tabular}

Fonte: elaborado pelos autores.

No núcleo "O preconceito está em nós desde que somos crianças": questões relacionadas aos sujeitos LGBT, estão reunidos sentidos relacionados aos sujeitos LGBT, sua aceitação ou não, e aqueles sentidos relacionados a ser gay, aceitar-se e ser aceito socialmente.

O professor julga que a bissexualidade é mais aceita que a homossexualidade: "Não tem um preconceito direto pelo fato dele ser gay ou não. Porque na cabecinha das pessoas interpretam que ele não é, a maioria pensa assim. Eu acho que não. Eu acho que é e tenta disfarçar que não. [...] eu acho que a aceitação é até um pouco melhor, mais fácil. Não tem um rótulo específico. Não sabe, e ai??". Sobre o não-reconhecimento da bissexualidade masculina, Seffner (2003, p. 131) ressalta que

[...] a masculinidade bissexual seria então uma identidade de fachada, não havendo sujeitos que possam preencher esta identidade [...]. O "verdadeiro" sujeito existente por trás do discurso bissexual seria um homossexual. Reafirma-se, aqui, a ideia de que a bissexualidade masculina é uma extensão da homossexualidade masculina. Mais ainda, aqueles situados nesse discurso seriam homossexuais mal vistos, uma vez que não "assumem" sua condição.

É preciso problematizar sentidos como esse, sobretudo vindos de um professor, com a intenção de buscar a construção de entendimentos que reconheçam a legitimidade da identidade bissexual. Além disso, o professor exprime sentidos que buscam explicar a diversidade sexual por meio de explicações biologizantes, como: "Se você for pensar na parte de Ciências, você vai levar em consideração isso: você é atraído por homem porque você tem mais hormônios femininos, e vice-versa", e "Em Ciências, quando você vai ensinar a parte de genética, hoje já até existe uma explicação genética né!”. Estas falas reforçam a necessidade de se problematizarem significados relacionados à sexualidade que 
permeiam práticas e discursos escolares, pois sugerir a gênese da homossexualidade nada mais é do que "deixar o preconceito falar, mesmo considerando a boa intenção científica ou moral" (SOUSA FILHO, 2009, p. 98).

O segundo núcleo, chamado "A escola ainda tem dificuldades em trabalhar temas fora do que é normal': diversidade sexual na escola, reúne sentidos acerca da educação sexual escolar e impressões sobre as relações entre alunos e professores. Assim como a professora, ele reconhece a mídia como uma fonte importante de informações sobre sexualidade: "Eu acho que ter um professor em sala de aula falando é menos impactante do que ele ir lá e ver a televisão".

O último núcleo: "Quando os alunos trazem ideias preconceituosas, fico sem reação": sexualidade e Ensino de Ciências, possui ideias relacionadas ao Ensino de Ciências, às práticas de educação sexual realizadas pelo professor, e sua formação.

Assim como a professora, ele indica nunca ter pensado em problematizar questões relacionadas à diversidade sexual em aula, expressando, ainda, que o assunto é delicado para ser abordado na escola. O professor também acredita que a sexualidade não deve se restringir ao Ensino de Ciências, indicando que "falta explorar das diversas maneiras, não somente da visão do professor de Ciências. O professor de Ciências vai falar da parte técnica". Nesta fala, se expressa um sentido que parece atribuir às Ciências a abordagem apenas de aspectos biológicos da sexualidade, cabendo a outras disciplinas a abordagem de outras questões.

De modo geral, os relatos das entrevistas apontam que o Ensino de Ciências parece possuir uma íntima relação, aos olhos de professores, diretores e alunos, com a solução de dúvidas e questionamentos que se referem à sexualidade. Mesmo com essa questão fazendo parte da prática pedagógica desses professores, poucos parecem assumir um compromisso com abordagem da sexualidade na escola, como parece ser o caso da professora entrevistada. A temática diversidade sexual não faz parte das práticas pedagógicas desses professores, sendo que suas ações que envolvem sexualidade parecem ainda se limitar à anatomia, aspectos médico-fisiológicos e preventivos.

O preconceito relacionado à diversidade sexual é indicado como algo presente nas relações da escola, e a professora parece não se calar diante de situações discriminatórias. Mesmo com esses sentidos que reconhecem as identidades LGBT e se indignam diante do preconceito sofrido por estes indivíduos, ambos os professores indicaram nunca terem pensando em problematizar essas questões em sala de aula.

Os relatos de situações de discriminação relacionadas a LGBT indicam que estas são cenas comuns no cotidiano escolar. A naturalização da homofobia leva à marginalização e humilhação cotidiana de alunos, professores e funcionários LGBT na escola, sendo necessário problematizar brincadeiras de cunho heteronormativo e homofóbico.

\section{Considerações finais}

Vem sendo atribuído, ao professor de Ciências, o papel de levar questões relacionadas à sexualidade para as salas de aula. É preciso reconhecer essa peculiaridade do Ensino de Ciências, visando o melhor preparo destes profissionais, para que sejam capazes de problematizar e sensibilizar os alunos quanto a sentidos preconceituosos e heteronormativos. 
Para que isto se efetive, é preciso que os cursos de formação inicial assumam a necessidade de problematizar e questionar os sentidos dos licenciandos em Ciências Biológicas relacionados à masculinidade/feminilidade, orientação sexual, identidade de gênero, entre outros temas.

De modo geral, os alunos consideram LGBT diferentes e, apesar de muitos deles se declararem não preconceituosos, seus sentidos expressam espanto, estranhamento, rejeição, repulsa e ódio com relação a esses sujeitos, sendo as travestis o grupo mais rejeitado e odiado.

Os professores acreditam que a escola é um lugar para formar novas percepções sobre a sexualidade e a diversidade sexual, mas as identidades LGBT ainda não fazem parte de discussões intencionalmente propostas por eles. Ambos disseram acreditar que o Ensino de Ciências possui um papel diferenciado, pois são reconhecidos como os únicos aptos a responderem questões relacionadas à sexualidade na escola. Pelos relatos, suas práticas parecem ser diferenciadas, sendo a do professor restrita a questões reprodutivas e preventivas, enquanto a professora parece incluir discussões também sobre padrões de gênero.

Significados religiosos aparecem fortemente nos sentidos dos alunos, e, também, são indicados pelos professores como entraves à abordagem da sexualidade no Ensino de Ciências. Um destes significados, que se expressa em muitas falas dos alunos, é a ideia de que o homem foi feito para a mulher e a mulher para o homem. Problematizar os significados relacionados à masculinidade e feminilidade parece ser um aspecto fundamental na busca da construção de sentidos que aceitem e respeitem os sujeitos LGBT.

Enquanto o Ensino de Ciências continuar a negligenciar a diversidade sexual em seus cursos de formação, dificilmente, teremos professores bem preparados e compromissados com a problematização de preconceitos na escola. Para que ocorram essas problematizações, é preciso que os professores, primeiramente, identifiquem e reflitam sobre seus sentidos relacionados ao tema.

Apesar de muitos significados socialmente difundidos promoverem a exclusão, marginalização e estigmatização de LGBT, a construção de sentidos que reconhecem a legitimidade dessas identidades é possível. Esses sentidos podem levar à alteração de significados sociais na direção do respeito à diversidade sexual e de gênero. Este processo não será simples, sendo necessário desvelar muitos significados que estabelecem a norma heterossexual que se encontram difundidos socialmente.

Sendo reconhecidos como aptos para a abordagem de temas relacionados à sexualidade, acreditamos que os professores de Ciências possam exercer um papel central na problematização e (re)construção de significados relacionados à diversidade sexual no ambiente escolar. Esta não é uma questão exclusiva dos professores de Ciências, mas como, geralmente, é o único momento de discussão sobre a sexualidade na escola, o Ensino de Ciências se configura como espaço privilegiado para que novos sentidos possam ser construídos com relação aos sujeitos LGBT, buscando o reconhecimento das orientações sexuais homo e bissexual e das diversas possibilidades de vivência da identidade transgênera. 


\section{Referências}

AGUIAR, W. M. J.; OZELLA, S. Núcleos de significação como instrumento para a apreensão da constituição dos sentidos. Psicologia: ciência e profissão, Brasília, v. 26, n. 2, p. 222-245, 2006.

ASBAHR, F. S. F. Sentido pessoal, significado social e atividade de estudo: uma revisão teórica. In: ENCONTRO BRASILEIRO DE EDUCAÇÃO E MARXISMO, 5., 2011, Florianópolis. Anais eletrônicos... Florianópolis: UFSC, 2001.

BOCK, A. M. B. A psicologia sócio-histórica: uma perspectiva crítica em psicologia. In: BOCK, A. M. B.; GONÇALVES, M. G. M.; FURTADO, O. (Org.). Psicologia sóciohistórica: uma perspectiva crítica em psicologia. São Paulo: Cortez, 2001. p. 15-35.

BONFIM, C. R. S. Educação sexual e formação de professores de ciências biológicas: contradições, limites e possibilidades. 2009. 267 f. Tese (Doutorado em Educação) Faculdade de Educação, Universidade Estadual de Campinas, Campinas, 2009.

BRAGA, E. R. M. "Palavrões" ou palavras: um estudo com educadoras /es sobre sinônimos usados na denominação de temas relacionados ao sexo. 2008. 240 f. Tese (Doutorado em Educação Escolar) - Universidade Estadual Paulista, Araraquara, 2008.

BRASIL. Ministério da Educação e do Desporto. Parâmetros curriculares nacionais: pluralidade cultural, orientação sexual. Brasília, 1997. v. 10.

FOUCAULT, M. História da sexualidade I: a vontade de saber. Rio de Janeiro: Graal, 1988.

FURLANI, J. Sexos, sexualidades e gêneros: monstruosidades no currículo da educação sexual. Educação em Revista, Belo Horizonte, n. 46, p. 269-285, 2007. Disponível em: <http://dx.doi.org/10.1590/S0102-46982007000200011>. Acesso em: 23 set. 2015.

JUNQUEIRA, R. D. Educação e homofobia: o reconhecimento da diversidade sexual para além do multiculturalismo liberal. In: . (Org.) Diversidade sexual na educação: problematizações sobre a homofobia nas escolas. Brasília: Ministério da Educação: UNESCO, 2009. p. 367-444. Disponível em: <http://www.defensoria.sp.gov.br/dpesp/ repositorio/39/diversidade_sexual_na_educacao_e_homofobia_nas_escolas.pdf $>$. Acesso em: 23 set. 2015.

LEONTIEV, A. N. O desenvolvimento do psiquismo. 2. ed. São Paulo: Centauro, 2004.

LOURO, G. L. Heteronormatividade e homofobia. In: JUNQUEIRA, R. D. (Org.). Diversidade sexual na educação: problematizações sobre a homofobia nas escolas. Brasilia: Ministério da Educação: UNESCO, 2009. p. 85-93.

. Pedagogias da sexualidade. In: LOURO, G. L. O corpo educado: pedagogias da sexualidade. Belo Horizonte: Autêntica, 2000. p. 7-34. 
MARIUZZO, T. Formação de professores em orientação sexual: a sexualidade que está sendo ensinada nas nossas escolas. 2003. 227 f. Dissertação (Mestrado) - Faculdade de Ciências, Universidade Estadual Paulista, Bauru, 2003.

MARTINS, L. M. A formação social da personalidade do professor: um enfoque vigotskiano. Campinas: Autores Associados, 2007.

MOTT, L. Por que os homossexuais são os mais odiados dentre todas as minorias? In: CORRÊA, M. et al. Gênero \& cidadania. Campinas: Pagu, 2002. p. 143-156.

SEFFNER, F. Derivas da masculinidade: representação, identidade e diferença no âmbito da masculinidade bissexual. 2003. 260 f. Tese (Doutorado em Educação) - Universidade Federal do Rio Grande do Sul, Porto Alegre, 2003.

SILVA, E. P. Q. Quando o corpo é uma (des)construção cultural. In: MARANDINO, M. et al. (Org.). Ensino de biologia: conhecimentos e valores em disputa. Niterói: Eduff, 2005. p. $141-150$.

SOUSA FILHO, A. Teorias sobre a gênese da homossexualidade: ideologia, preconceito e fraude. In: JUNQUEIRA, R. D. (Org.). Diversidade sexual na educação: problematizações sobre a homofobia nas escolas. Brasília: Ministério da Educação: UNESCO, 2009. p. 95-124.

VYGOTSKY, L. S. A construção do pensamento e da linguagem. São Paulo: Martins Fontes, 2000. 